Research Article

\title{
DETERMINING EFFECTS OF HEAT TRANSFER FINS ON THE SOLIDIFICATION PROCESS OF PCM AND NANO-PCM WITH A RECTANGULAR COOLER
}

\author{
Besir KOK ${ }^{*}$, Mert GÜRTÜRK ${ }^{2}$
}

\begin{abstract}
In this study, the performances of the heat transfer fins during the solidification processes of $\mathrm{PCM}$ and nano-PCMS( $\left.\mathrm{Al}_{2} \mathrm{O}_{3}-\mathrm{CuO}\right)$ were investigated. These two situations were considered for both with and without fins. Two different heat transfer fins were considered in the study. The investigation was carried out using both experimental (for Base-PCM) and numerical methods. The results showed that the effects of heat transfer fins were limited due to the overcooling effect of PCMs. The solidification process of Base-PCM in the heat storage tank ended in 10 minutes, while the solidification time of the PCM was determined as 11 minutes by using the Fin 1 design. The solidification process in the heat storage tank with nano-PCM $(\mathrm{CuO})$ was realized in 13 minutes with the Fin 1 design.
\end{abstract}

Key words: PCM; Fin; TES; Solidification

\section{Introduction}

In the literature, there are many studies designed and examined for the solidification process of PCM in the TES. For example, heat transfer fluid was passed through a cylindrical cooler placed in a cylindrical heat storage tank. The solidification process of PCM which is in the liquid phase between the cooler and heat storage walls was investigated. The temperature and liquid mass fraction values of PCM were discussed in that study. In the study, corrugated heat transfer fins were designed to improve the solidification process of PCM [1]. When the studies in the literature are examined, it is seen that the most commonly used heat transfer fin type is rectangular. In one of those studies, rectangular heat transfer fins were used to accelerate the solidification time of a PCM in the liquid phase. By changing the placement of those fins in the heat reservoir, many parameters were considered during the solidification of the PCM. These parameters are temperature fields, current lines and solid fraction. All those values were taken into consideration in the solidification process of PCM based on time [2]. In many studies examined in the literature, it is seen that heat storage geometry is cylindrical. Innovative fins were designed to the solidification of PCM, which is in the liquid phase, in a cylindrical heat reservoir. Many parameters were considered examining the effects of those fins and PCM on the solidification process. Those parameters such as solidification time, temperature distribution, total solidification time were examined [3]. Many numerical methods are used to examine the solidification process of PCM. It is seen that different strategies are followed in those methods. Approaches such as the use of adaptive mesh structure and porosity evaluation of the surface between solid and liquid phase PCM are adopted. Using the adaptive mesh structure, contour of values such as the solidification process, total energy, solid fraction in a TES were formed and examined [4]. In some studies, the solidification process of PCM was examined by considering the heat storage design. In one of those

\footnotetext{
${ }^{1}$ Technical Vocational School, Frrat University, Elazig, Turkey, (besirkok@ gmail.com) (DD https://orcid.org/0000-0001-7241-952X

2 Department of Energy Systems Engineering, Technology Faculty, Firat University, Elazig, Turkey, (m.gurturk@gmail.com) https://orcid.org/0000-0003-0380-5704
} 
studies, the solidification process of PCM in thermal energy storage, which is a triplex tube, was investigated [5]. The same researchers conducted a similar study to accelerate the melting time of PCM [6]. In a similar heat store, a study was carried out considering the natural convection occurring during the solidification process. In the study, the solidification process of PCM, which is in the liquid phase, between heat reservoir and heat transfer fins made from aluminum was examined. The parameters such as liquid fraction, minimum temperature value, average temperature value, which depend on time, were considered [7]. As mentioned before, it is emphasized that there are many studies on various heat transfer fin designs during the solidification process of PCM. In one of those studies, various analyses were carried out considering the variable thickness parameters of the heat transfer fins. In those analyses, parameters such as solidification time, solid fraction and temperature contour were examined [8]. In the fin designs studied so far, the heat transfer fins have a non-porous structure. Studies were conducted on the effects of heat transfer fins, which have a foam structure, on the solidification process of PCM [9]. In the last study discussed in the introduction part of the study, the effects of $\mathrm{V}$ shape heat transfer fins on the solidification process of PCM were investigated. The researchers examined the solidification process of PCM in the heat reservoir with a numerical study [10].

In this study, the effects of heat transfer fins placed in the heat storage tank, which is rectangular geometry, on the solidification process of PCM were investigated. However, the effects of the fins designs on the solidification process of the PCM and nano-PCM were examined in this study.

\section{Material and Methods}

Two different heat transfer fins were considered. The effects of these designed fins on the solidification process of PCM were investigated. The effects of the designed Fin 1 are compared with the effects of the heat transfer Fin 2 placed throughout the heat reservoir, which are highly preferred in the literature, to the melting of the PCM. In this study, by adding nanoparticle particles to PCM, the thermophysical properties of paraffin wax were changed. The main purpose of nano-material adding into PCM is to obtain PCMs with poorer thermophysical properties. For this reason, many nano-PCM studies have been investigated and it is seen that mixing high amounts of nanomaterial with PCM has a bad effect on the heat storage property of PCM. The experimental study was used to determine the validation process of the numerical model. The solidification of PCM in the heat storage was experimentally carried out. The flow diagram of the experimental setup used in the experiments is shown in Fig. 1.

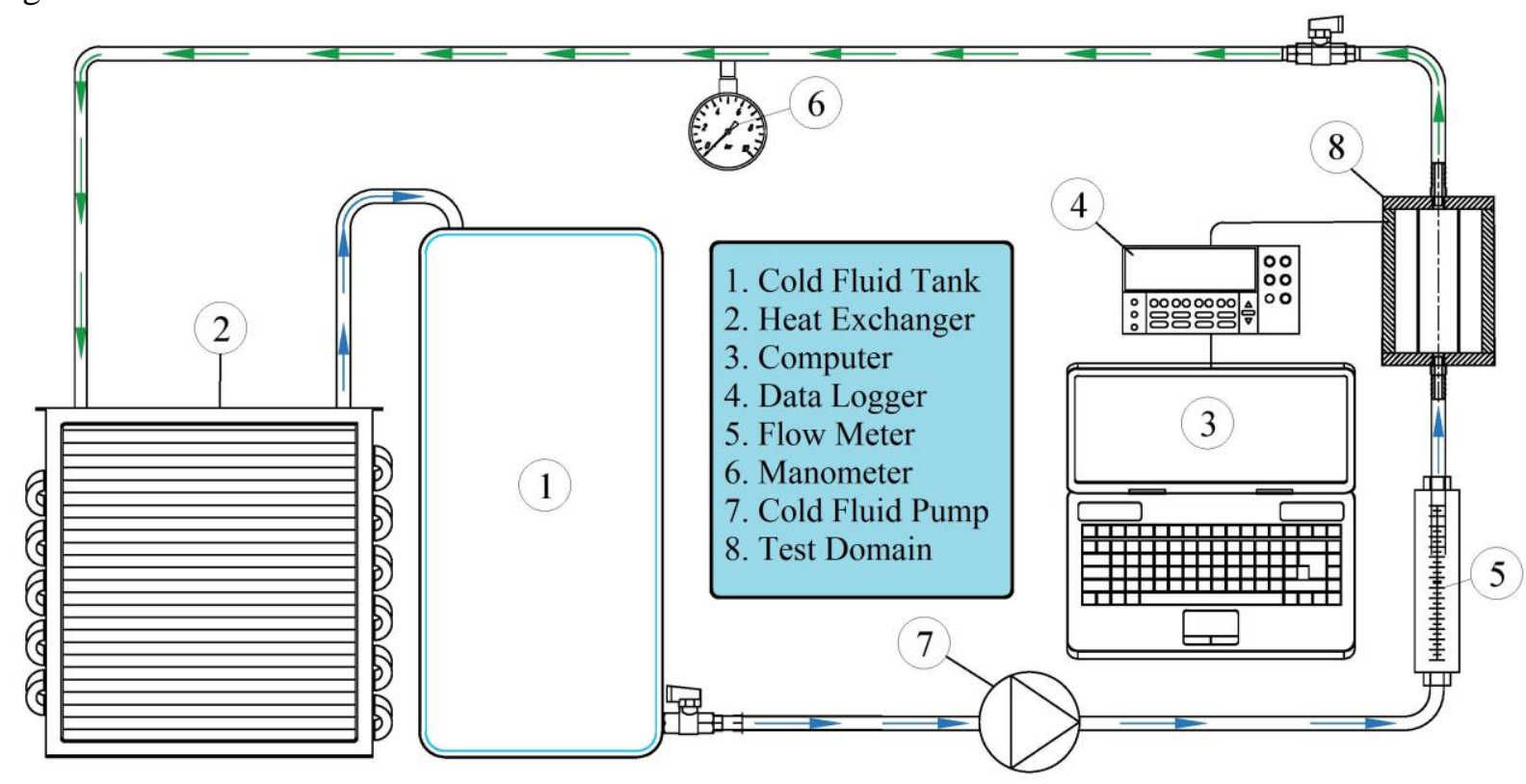

Figure 1. Experimental setup 
During the discharge process of the thermal energy in the heat reservoir, water was sent by a circulation pump. The heated water in the TES is sent back to the cold water tank before being sent to the heat storage tank. The desired water temperature value is provided again by the cooling system. In the experiment setup, the measured temperature values were transferred to the computer with a datalogger. The flow rate of the circulating water in the system is $2.5 \mathrm{~kg} / \mathrm{s}$. The flow rate is controlled by a flow meter. Detailed drawings and boundariy conditions of the tact -1

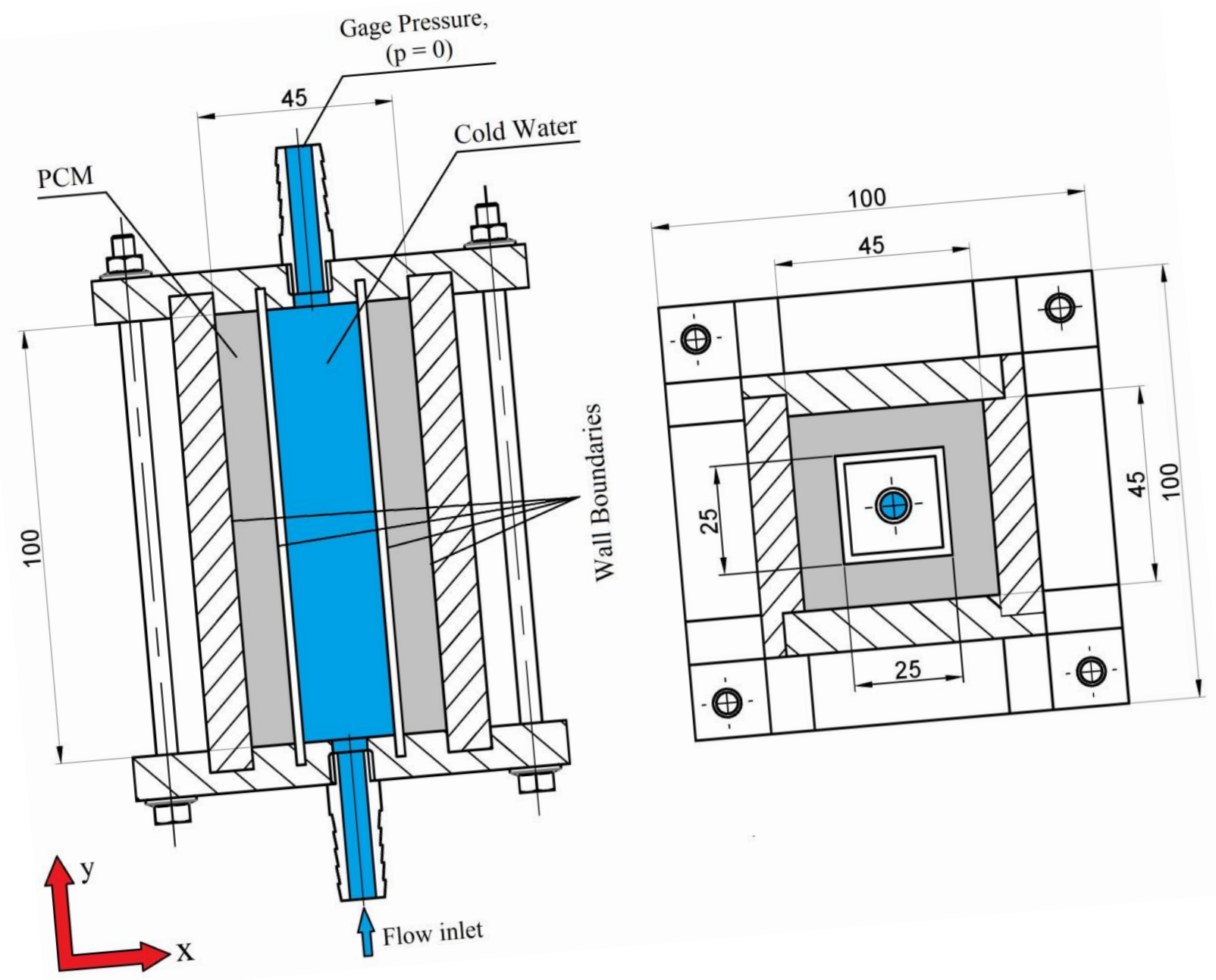

Figure 2. Detailed drawings and boundariy conditions of the test domain

The figure shows the dimensions of the test domain. All dimensions are in millimeters. The cooler is rectangular and the refrigerant passes through this channel. There is PCM in the liquid phase in between the rectangular cooler and walls of the heat storage tank. The heat transfer fins considered in the scope of the study are shown in Fig. 3. The Fin 2 design shown in Fig. 3 is the most widely used heat transfer fin-type in the literature.

The heat conductive coefficient of PCM used in the experiments was determined by using KD2pro device. PCM (paraffin wax) used in the study has a heat conduction coefficient of $0.3 \mathrm{~W} / \mathrm{m}$. $\mathrm{K}$ for the solid phase and $0.095 \mathrm{~W} / \mathrm{m} \cdot \mathrm{K}$ for the liquid phase. The heat conduction coefficient was measured experimentally using KD2'pro instrument. The instruments used in all measurement applications were first calibrated and then necessary measurements were made. The error rate of the device used to determine the thermal conductivity value is 0.0287 . The melting temperature of the paraffin wax varies between 52 and $55^{\circ} \mathrm{C}$. The viscosity and density of PCM 
used in the experiments were determined by the following equations. The density, the heat capacity, the viscosity, the thermal conductivity of the nano-PCMs are determined by using equations in Table 1 .

Fin 1 Fin 2

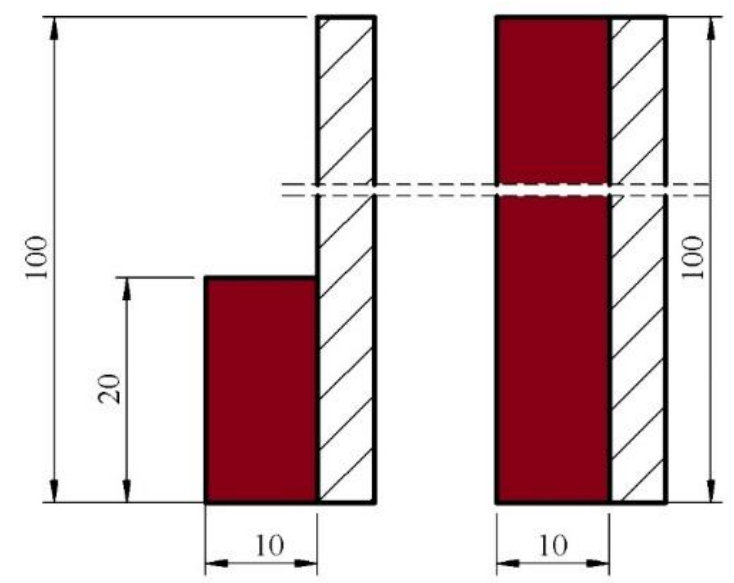

Figure 3. Heat transfer fins considered in the scope of the study

Table 1. Used equations

\begin{tabular}{lc} 
The density (PCM) [11, 12] & $\rho=\frac{750}{0.001(T-319.15)+1}$ \\
The viscosity (PCM) [11, 12] & $v=0.001 \exp \left(-4.25+\frac{1790}{T}\right)$ \\
\hline The density (nano-PCMs) [13] & $\rho_{n P C M}=(1-\Phi) \rho_{P C M}+\Phi \rho_{p}$ \\
\hline The heat capacity (nano-PCMs) [11] & $\left(\rho C_{p}\right)_{n P C M}=(1-\Phi)\left(\rho C_{p}\right)_{P C M}+\Phi\left(\rho C_{p}\right)_{p}$ \\
The viscosity (nano-PCMs) [11] & $\frac{\mu_{n P C M}=\frac{\mu_{n P C M}}{(1-\Phi)^{2.5}}}{k_{n P C M}}=\frac{k_{p}+2 k_{P C M}-2 \Phi\left(k_{P C M}-k_{p}\right)}{k_{p}+2 k_{P C M}+\Phi\left(k_{P C M}-k_{p}\right)}$ \\
The thermal conductivity (nano-PCMs) [11]
\end{tabular}

Table 2 presents the density, specific heat capacity, thermal conductivity and viscosity values for base-PCM, Nano 1 - PCM (Paraffin Wax $+\mathrm{Al}_{2} \mathrm{O}_{3}$ ) and Nano 2 - PCM (Paraffin Wax $+\mathrm{CuO}$ ). The table shows these properties for $25^{\circ} \mathrm{C}$ (solid phase) and $70{ }^{\circ} \mathrm{C}$ (liquid phase). However, these values were calculated at $5{ }^{\circ} \mathrm{C}$ intervals between $25{ }^{\circ} \mathrm{C}$ and $85{ }^{\circ} \mathrm{C}$ and the boundary conditions were defined for these values in the program.

Table 2. Thermophysical properties of Base and Nano PCMs

\begin{tabular}{|c|c|c|c|c|c|c|c|c|}
\hline & \multicolumn{2}{|c|}{$\begin{array}{l}\text { Nano } \\
\text { Particles }\end{array}$} & \multicolumn{2}{|c|}{$\begin{array}{l}\text { Base-PCM } \\
\text { (Parafin Wax) }\end{array}$} & \multicolumn{2}{|c|}{$\begin{array}{l}\text { Nano } 1 \text { - PCM } \\
\left(\text { Parafin } \mathrm{Wax}+\mathrm{Al}_{2} \mathrm{O}_{3}\right)\end{array}$} & \multicolumn{2}{|c|}{$\begin{array}{l}\text { Nano } 2 \text { - PCM } \\
(\text { Parafin Wax }+\mathrm{CuO})\end{array}$} \\
\hline & $\mathrm{Al}_{2} \mathrm{O}_{3}$ & $\mathrm{CuO}$ & $\begin{array}{l}\text { Solid } \\
\left(25^{\circ} \mathrm{C}\right)\end{array}$ & $\begin{array}{l}\text { Fluid } \\
\left(70^{\circ} \mathrm{C}\right)\end{array}$ & $\begin{array}{l}\text { Solid } \\
\left(25^{\circ} \mathrm{C}\right)\end{array}$ & $\begin{array}{l}\text { Fluid } \\
\left(70^{\circ} \mathrm{C}\right)\end{array}$ & $\begin{array}{l}\text { Solid } \\
\left(25^{\circ} \mathrm{C}\right)\end{array}$ & $\begin{array}{l}\text { Fluid } \\
\left(70^{\circ} \mathrm{C}\right)\end{array}$ \\
\hline$\rho\left(\mathrm{kg} / \mathrm{m}^{3}\right)$ & 2702 & 8933 & 766 & 732 & 862.8 & 830.5 & 1174.4 & 1142 \\
\hline $\begin{array}{l}\mathbf{C p}(\mathbf{J} / \mathbf{k g} \\
\mathbf{K})\end{array}$ & 903 & 385 & 2140 & 2580 & 1946.3 & 2307.2 & 1472.5 & 1721.5 \\
\hline
\end{tabular}




\begin{tabular}{|c|c|c|c|c|c|c|c|c|}
\hline $\mathbf{k}(\mathbf{W} / \mathbf{m} \mathbf{K})$ & 237 & 401 & 0.3 & 0.095 & 0.3471 & 0.11 & 0.3473 & 0.11 \\
\hline$\mu(\mathrm{kg} / \mathrm{m} \mathrm{s})$ & - & - & - & $2.6 \times 10^{-3}$ & - & $3 \times 10^{-3}$ & - & $3 \times 10^{-3}$ \\
\hline
\end{tabular}

The enthalpy of the phase change material is calculated by using Eq. (1) [14].

$$
L H=h+\Delta L H
$$

$h$ indicates the sum of the sensible enthalpy and LH is the latent heat.

$$
\frac{\partial}{\partial t}(\rho H)+\nabla \cdot(\rho \vec{v} L H)=\nabla \cdot(k \nabla T)+S
$$

where $\rho, \vec{v}$ and $S$ are density, fluid velocity and source term, respectively. ANSYS FLUENT solve numerically continuity, momentum and energy equations by meant the finite volume method. The SIMPLE algorithm uses a relationship between velocity and pressure corrections to enforce mass conservation and to obtain the pressure field [14].

In this study, a rectangular cooler was placed in a rectangular heat tank. The PCM in the liquid phase was left to the volume remaining between the heat storage tank and the cooler.

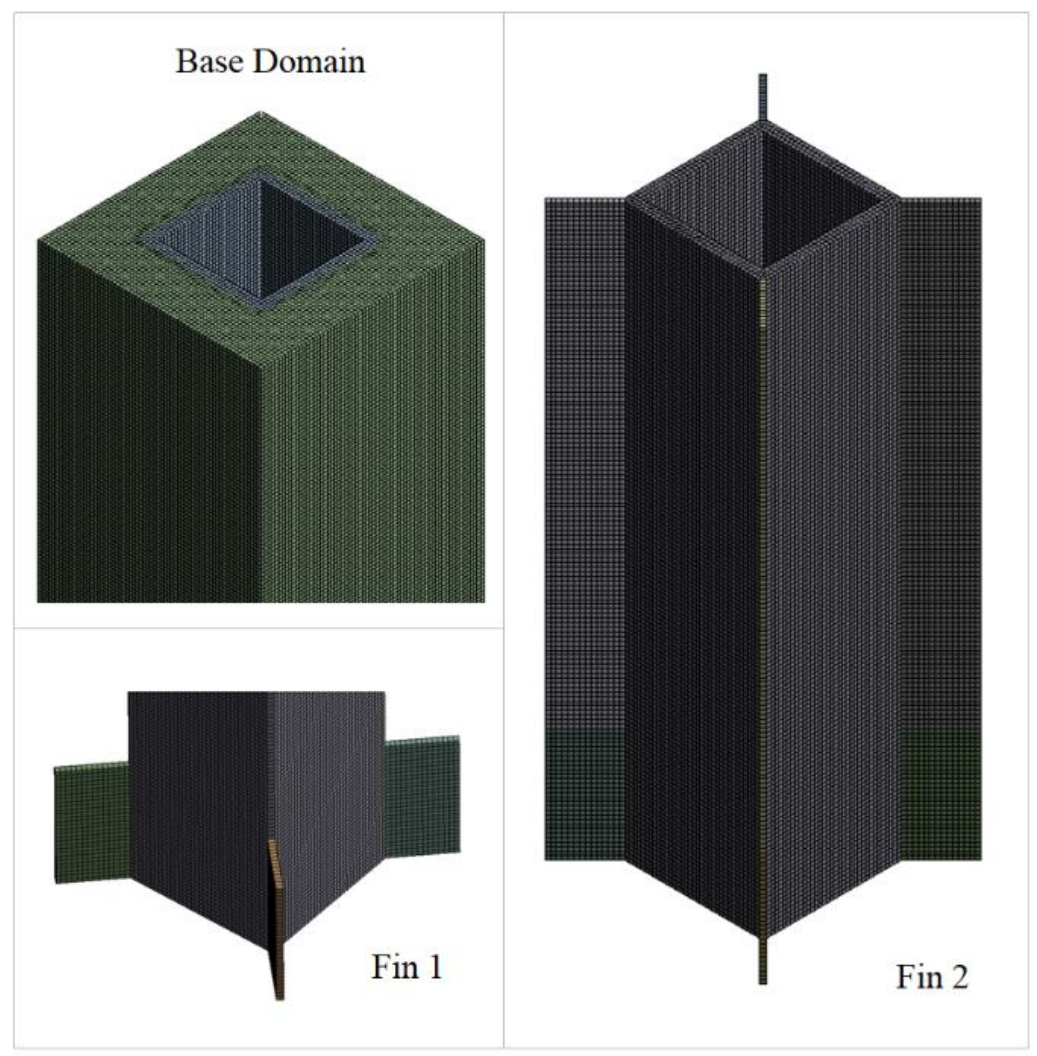

Figure 4. Mesh structure

The solidification process of PCM in the liquid phase was investigated by passing cold water through the rectangular cooler. The numerical method was used in the analysis and the mesh structure of the geometry was formed. Illustrations of the mesh structures formed are shown in Fig. 4. Fig. 4 shows mesh structures of the special heat transfer Fin 1 designed, Base-PCM (without fin) and heat transfer Fin 2 which is preferred in the literature. It is seen that the formed mesh structures are homogeneous and have a smooth transition between the mesh structures. A suitable mesh structure for CFD analysis of the problem has been obtained with the optimization of these different element numbers and mesh models. The liquid fraction values obtained for the different mesh structures and element numbers are given in Fig. 5. 


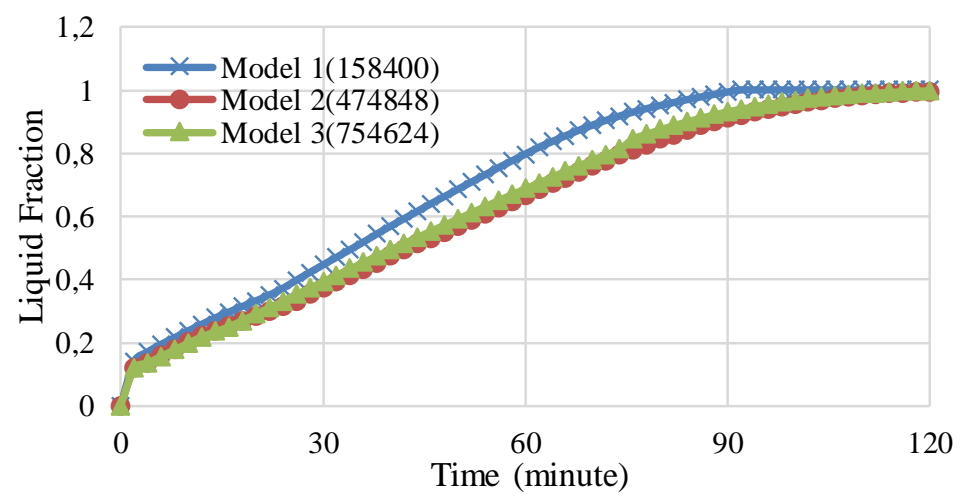

Figure 5. Comparison of CFD models created according to different network structures and to liquid fraction values

The data obtained from numerical and experimental measurements were taken into consideration and validation of the numerical model was performed. In Fig. 6, the temperature values obtained from numerical and experimental studies are compared with each other.

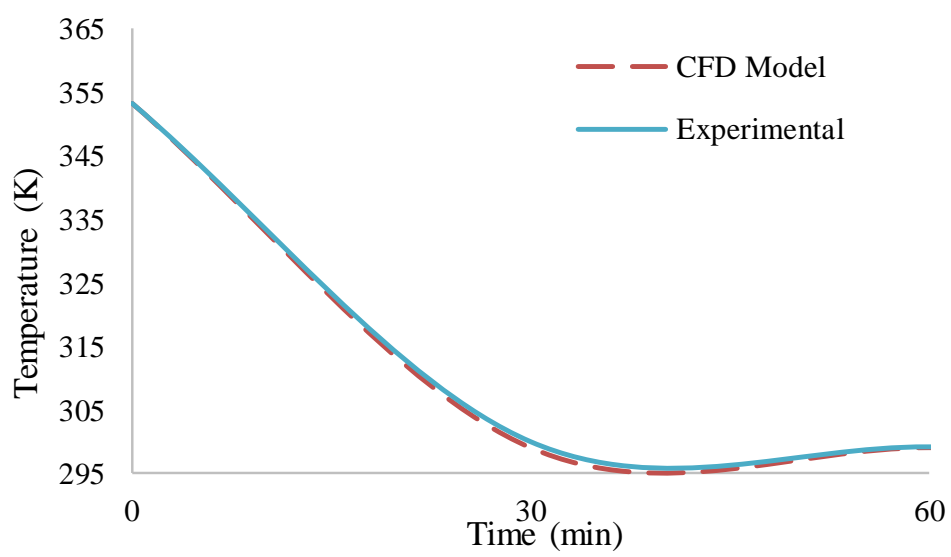

Figure 6. Comparison of temperature values of both experiment and numerical measurements

The results obtained from experimental and numerical analyses are very close to each other. This proves the reliability of the numerical model. The results obtained from the verification study of the numerical model show the accuracy of the method followed in the creation of the numerical model. Base_Al $\mathrm{Al}_{2} \mathrm{O}_{3}$, Base_CuO, Fin 1, Fin 2 ve Fin 1_CuO numerical models were created by using the same method.

\section{Results and Discussion}

The solidification of the PCM is important as well as the melting of the PCM. Many studies have been conducted examining the discharge process of thermal energy during the solidification process of PCM. In this study, the effects of the specially designed fin on the solidification process of Base-PCM and nano-PCM were investigated by numerical analysis. Heat storage tank (without fin) was considered for three different situations. These three different situations are Base-PCM, Base_ $\mathrm{Al}_{2} \mathrm{O}_{3}$ and Base_CuO. Fig. 7 below shows the mass fraction obtained from the solidification process in the thermal energy storage in these three cases. 


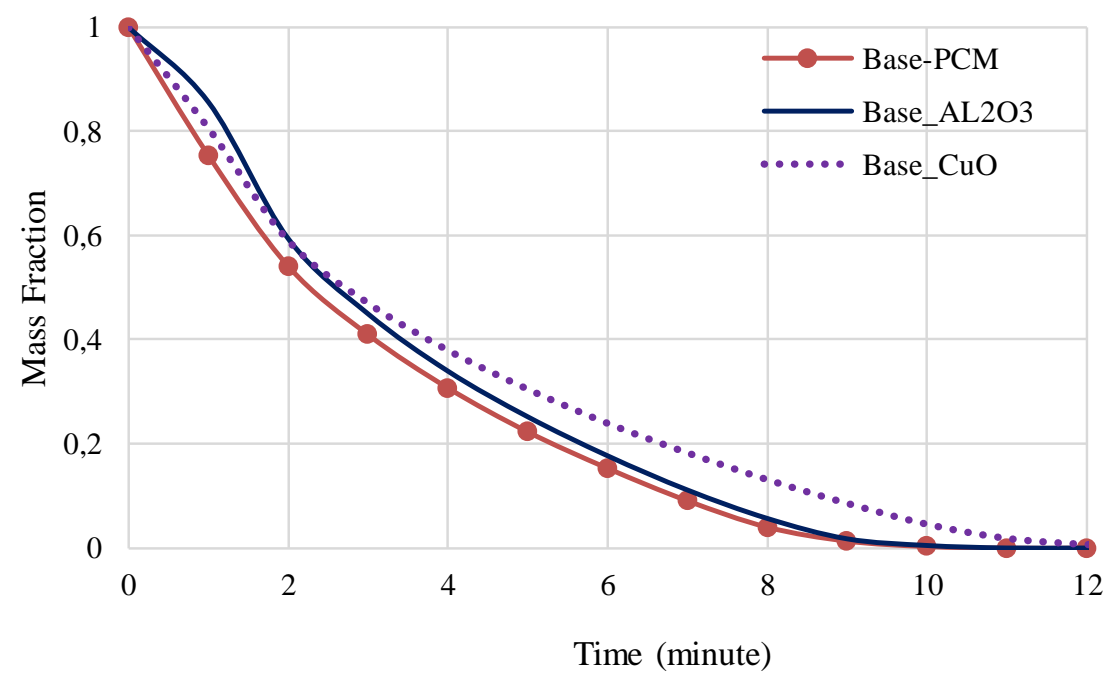

Figure 7. Base-PCM and nano_PCMs $\left(\mathrm{CuO}\right.$ and $\left.\mathrm{Al}_{2} \mathrm{O}_{3}\right)$ solidification process in a thermal energy storage

The figure shows the time-varying mass fraction for Base-PCM and nano-PCMs. in Fig. 7, the value 1 in the y-axis shows that the whole of PCM in the thermal heat store is in the liquid phase. 0 indicates that the whole of PCM is in the solid phase. The data obtained show that Base-PCM performed best. The solidification process was realized with Base-PCM in the shortest time. In the literature, it has been emphasized that the main purpose of using nano-PCM is to improve the thermophysical properties of PCM. The use of $\mathrm{CuO}$ at more than $1 \%$ causes negative effects on the thermophysical properties of PCMs [12]. In the solidification process, similar results were obtained in the literature. When the graph in Fig. 7 is examined, the worst solidification process is obtained with Base_CuO. In this study, numerical models have been formed and the solidification processes of Base-PCM, Fin 1 and Fin 2 were examined. The results are shown in Fig. 8.

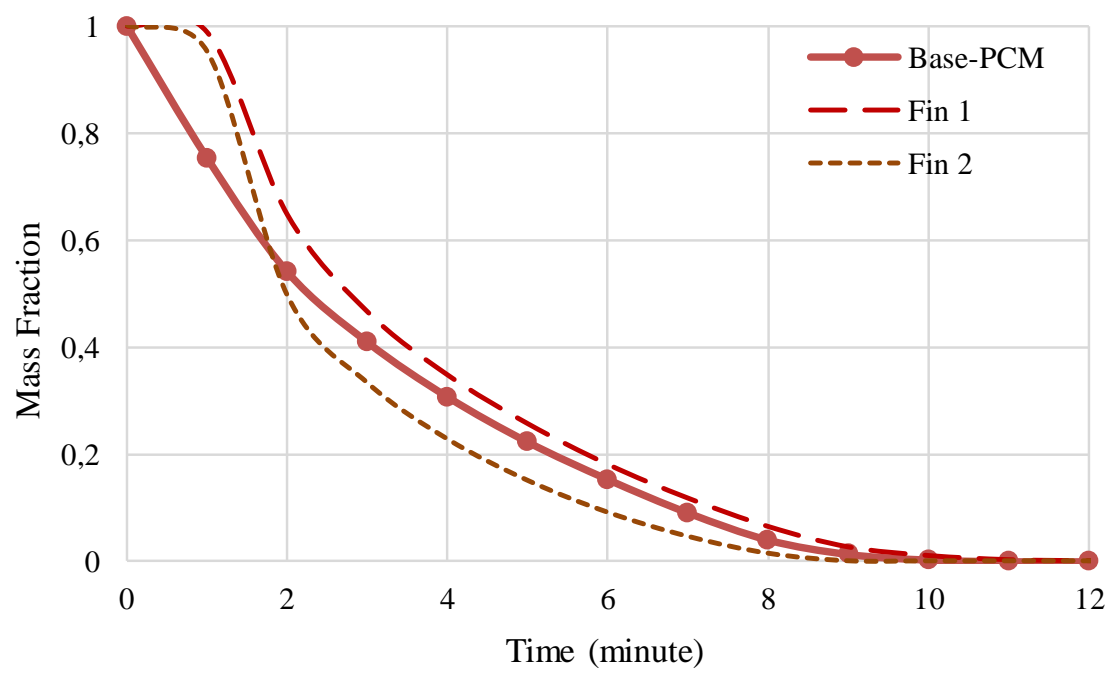

Figure 8. Time-dependent variation of the solidification process of PCM in thermal energy tanks with and without fins

As shown in Fig. 8, the Fin 2 design performed best in solidifying paraffin wax. The absence of heat transfer fins in the Base PCM model increases the discharge time of the energy stored in the PCM. This relates to the area of the cooling surface during the transfer of heat. Heat transfer fins in the thermal energy discharge process of PCMs perform better because they increase the surface area of the cooling 
or heating surface. The worst in the solidification process was obtained with Fin 1. Fig. 9 shows the values for the solidification process in the cases of Base_CuO, Fin 1_CuO and Base-PCM.

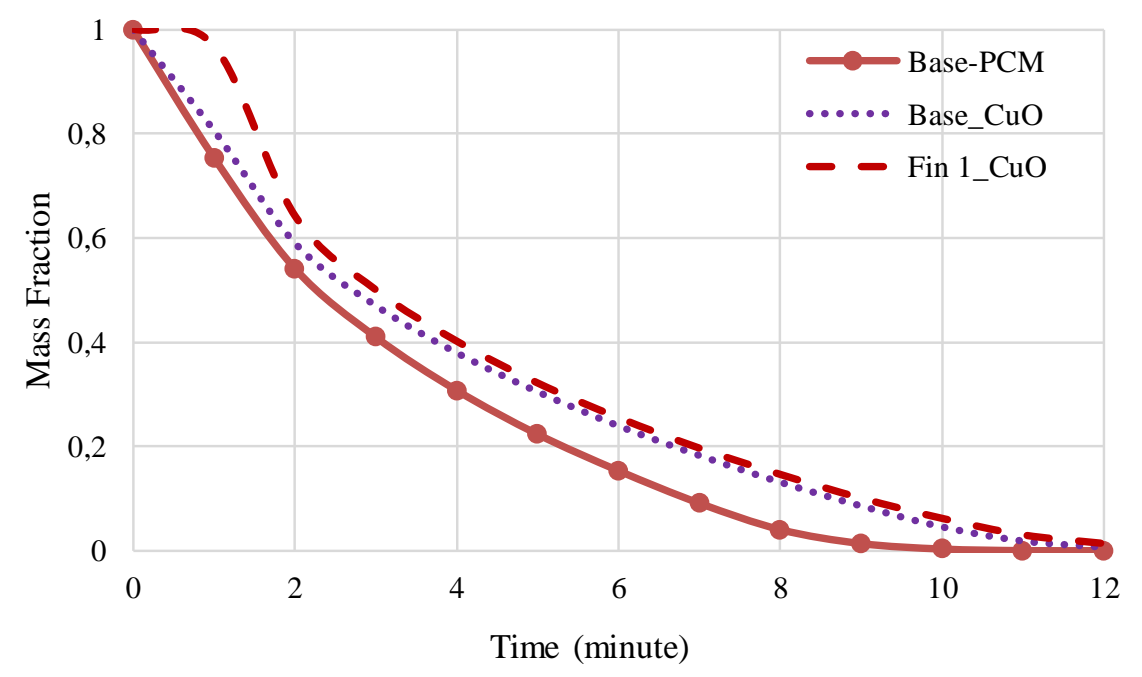

Figure 9. Time-dependent variation of the solidification process of Base_CuO, Fin 1_CuO and Base-PCM

When the solidification processes in Fig. 9 were examined, Base-PCM showed the best performance. Solidification in Base-PCM ended in 10 minutes. Solidification times of Fin 1_CuO and Base_CuO are 13 minutes. The solidification process of PCMs refers to the process of discharging thermal energy. The absence of a heat transfer fins in the PCM model increases the discharge time of the thermal energy stored in the PCM. This complicates the discharge of energy from the PCM in regions away from the cooling surface. High concentrations of nano-PCM $(\mathrm{CuO})$ have negative effects on cooling. The non-fin Base-PCM model performed better during the solidification process of the PCM. Although the Fin 1_CuO model had heat transfer fins, the solidification process took longer than the Base_PCM model in Fig. 9. The energy stored as both sensible and latent heat is discharged during the solidification process of the PCM. As can be seen in many sources in the literature, it has been reported that overcooling occurs during the solidification process of PCM. As seen in this study, it was observed that PCM and nano_PCM solidified under the effects of overcooling in a very short period of time. 


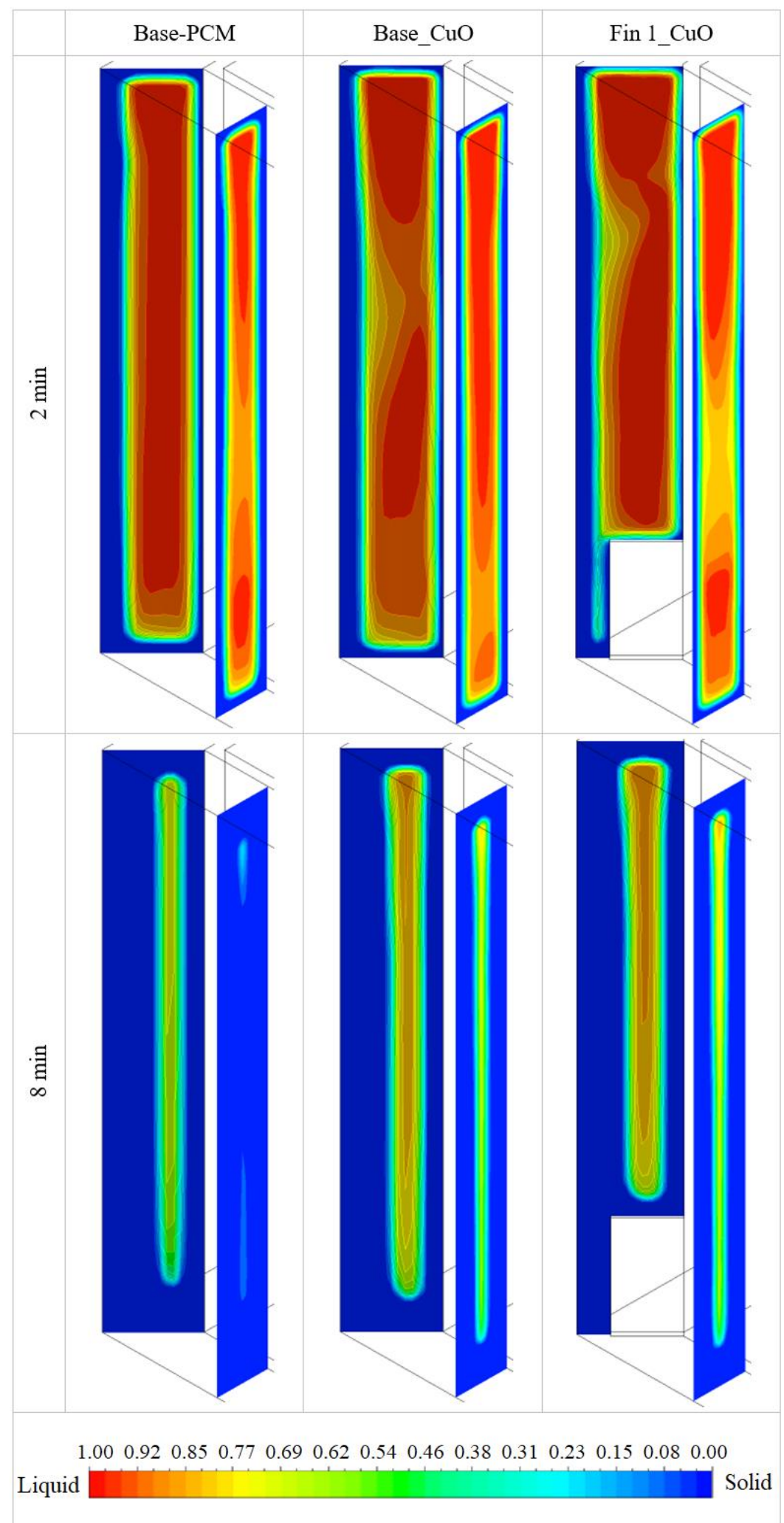

Figure 10. Solidification process of Base-PCM, Base_CuO and Fin 1_CuO

The solidification process of Base-PCM, Base_CuO and Fin 1_CuO, which solidify in a very short period of time, on two different planes in the heat storage are shown in Fig. 10. In parallel with the graph of Fig. 9, the values in Fig. 10 are similar. It can be said that the heat transfer Fin 1 has no effect on the solidification process. In general, there is no significant difference between the best performing and the worst-performing models during the solidification process. The main reason for this is the effects of overcooling. This can be better illustrated in Fig. 11. 


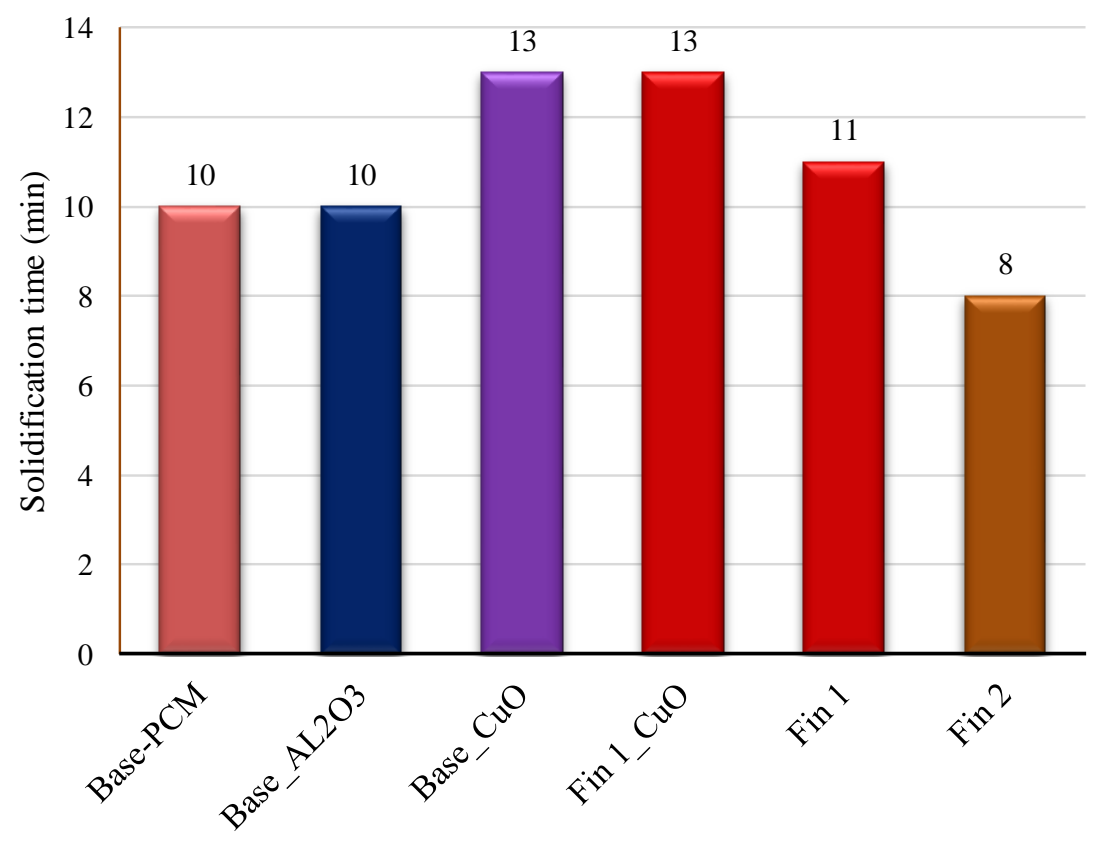

Figure 11. Solidification time of all models

When the data obtained are examined, it is seen that the effects of the special heat transfer fins in the solidification process of PCM are limited. When the data on the solidification process in Fig. 11 is examined, the best solidification was obtained with Fin 2 at $8 \mathrm{~min}$, while the worst solidification process was at 13 minutes with Base_CuO and Fin 1_CuO. As shown in Figs 8-11, the Base_PCM model performed better than Base_CuO, Fin 1_CuO and Fin 1 models.

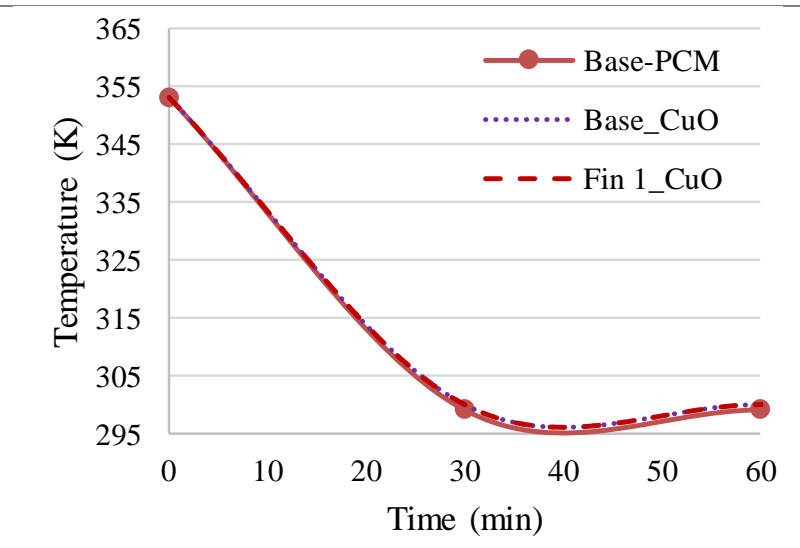

Top

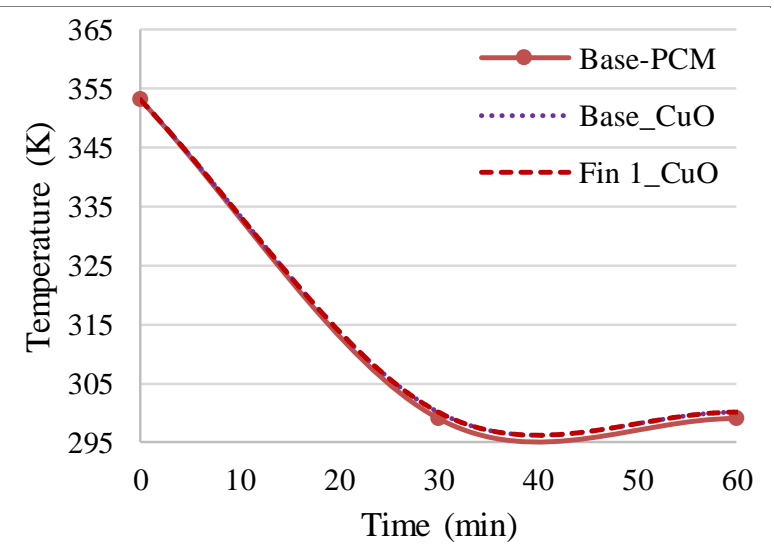

Middle

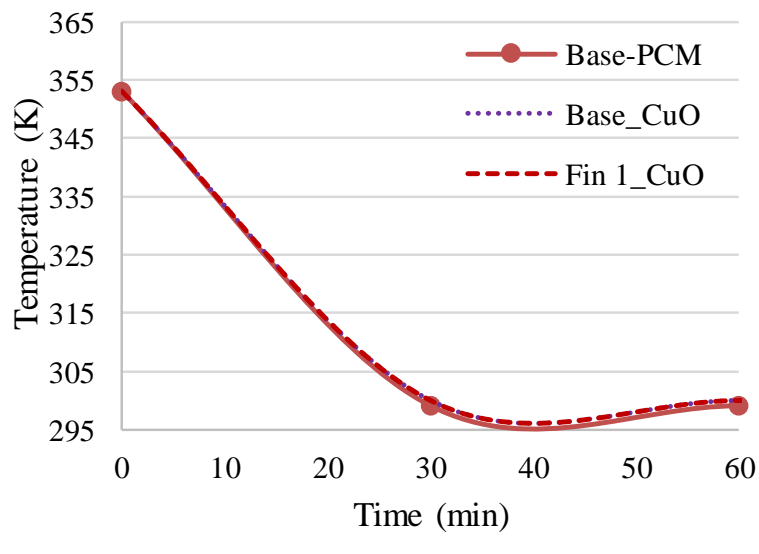

Bottom 
Figure 12. Temperature values at different point of the thermal energy storage

The difference between the best and the worst is only 5 minutes due to the effects of overcooling. The data examined up to this part of the article is related to the discharge process of the latent heat of the PCM. Sensible heat discharge of PCMs is obtained by considering temperature graphs. Fig. 12 shows the temperature graphs of Base-PCM, Fin 1_CuO and Base_CuO. Fig. 12 shows the temperature values at different points within the thermal energy storage. There is almost no difference between the temperature values for all three cases. The discharge time of the sensible heat in the Thermal Energy Storage (TES) ended at about 40. Min. When parameters in Fig. 12 are considered, it is understood that there is no difference between the temperature values at different points in the TES. As with latent heat, the effects of overcooling can be seen during the discharge of sensible heat. As a result, Fin 1 has a limited effect on the solidification process of PCM and nano-PCM. This comment can be observed in the process that occurs during the discharge of both sensible and latent heat.

\section{Conclusion}

In this study, the effects of these fins on the solidification process of PCM were investigated.

- The effect of Fin 1 on the solidification processes of PCM and 1\% prepared nano-PCM $(\mathrm{CuO})$ was very limited.

- With the Fin 1 design, the solidification of the nano-PCM $(\mathrm{CuO})$ was achieved in 13 minutes. This process showed that the latent heat of nano-PCM with Fin 1 was discharged at 13 min, but the sensible energy of the nano_PCM with Fin 1 was discharged at 40 min.

- The solidification process of Base-PCM ended in $11 \mathrm{~min}$ by using Fin 1. The solidification process of Base-PCM is 10 minutes. In view of these two conditions, the Fin 1 design has not a positive contribution to the solidification process of paraffin wax.

- The findings show that the effects of heat transfer fins may be limited due to the overcooling effect of PCM and nano-PCM. However, it should be emphasized that this may also vary according to the size of the thermal heat store and the amount of PCM.

\section{Nomenclature}

B liquid fraction

$C_{p} \quad$ specific heat capacity $(\mathrm{J} / \mathrm{kg} \cdot \mathrm{K})$

g gravity $\left(\mathrm{m} / \mathrm{s}^{2}\right)$

$h \quad$ enthalpy $(\mathrm{J} / \mathrm{kg})$

$k \quad$ thermal conductivity $(\mathrm{W} / \mathrm{m} \cdot \mathrm{K})$

L length (m)

LH laten heat $(\mathrm{J} / \mathrm{kg})$

S source term

T temperature (K)

t time (s)

$\vec{v} \quad$ velocity $(\mathrm{m} / \mathrm{s})$

$v \quad$ viscosity $\left(\mathrm{Ns} / \mathrm{m}^{2}\right)$

Greek letters
$\mu \quad$ viscosity $\left(\mathrm{Ns} / \mathrm{m}^{2}\right)$
$\rho \quad$ density $\left(\mathrm{m}^{3} / \mathrm{kg}\right)$ 
$\Phi \quad$ particle concentration

Subscripts

ref reference

PCM phase change material

nPCM nano phase change material

$\mathrm{p} \quad$ pressure

\section{References}

[1] Aly KA, El-Lathy AR, Fouad MA (2019) Enhancement of solidification rate of latent heat thermal energy storage using corrugated fins. J Energy Storage 24:100785 . doi: 10.1016/j.est.2019.100785

[2] Jmal I, Baccar M (2018) Numerical investigation of PCM solidification in a finned rectangular heat exchanger including natural convection. Int J Heat Mass Transf 127:714-727 . doi: 10.1016/j.ijheatmasstransfer.2018.08.058

[3] Liu S, Peng H, Hu Z, et al (2019) Solidification performance of a latent heat storage unit with innovative longitudinal triangular fins. Int $J$ Heat Mass Transf 138:667-676 . doi: 10.1016/j.ijheatmasstransfer.2019.04.121

[4] Sheikholeslami M (2018) Numerical modeling of nano enhanced PCM solidification in an enclosure with metallic fin. J Mol Liq 259:424-438 . doi: 10.1016/j.molliq.2018.03.006

[5] Mahdi JM, Nsofor EC (2018) Solidification enhancement of PCM in a triplex-tube thermal energy storage system with nanoparticles and fins. Appl Energy 211:975-986 . doi: 10.1016/j.apenergy.2017.11.082

[6] Mahdi JM, Lohrasbi S, Ganji DD, Nsofor EC (2018) Accelerated melting of PCM in energy storage systems via novel configuration of fins in the triplex-tube heat exchanger. Int J Heat Mass Transf 124:663-676 . doi: 10.1016/j.ijheatmasstransfer.2018.03.095

[7] Sefidan AM, Sojoudi A, Saha SC, Cholette M (2017) Multi-layer PCM solidification in a finned triplex tube considering natural convection. Appl Therm Eng 123:901-916 . doi: 10.1016/j.applthermaleng.2017.05.156

[8] Hosseinzadeh K, Alizadeh M, Tavakoli MH, Ganji DD (2019) Investigation of phase change material solidification process in a LHTESS in the presence of fins with variable thickness and hybrid nanoparticles. Appl Therm Eng 152:706-717 . doi: 10.1016/j.applthermaleng.2019.02.111

[9] Yang X, Niu Z, Bai Q, et al (2019) Experimental study on the solidification process of fluid saturated in fin-foam composites for cold storage. Appl Therm Eng 161:114163 . doi: 10.1016/j.applthermaleng.2019.114163

[10] Alizadeh M, Hosseinzadeh K, Shahavi MH, Ganji DD (2019) Solidi fi cation acceleration in a triplex-tube latent heat thermal energy storage system using V-shaped fi $\mathrm{n}$ and nano-enhanced phase change material. Appl Therm Eng 163:114436 . doi: 10.1016/j.applthermaleng.2019.114436

[11] Valan Arasu A, Sasmito AP, Mujumdar AS (2011) Thermal performance enhancement of paraffin wax with AL $2 \mathrm{O} 3$ and $\mathrm{CuO}$ nanoparticles - A numerical study. Front Heat Mass Transf 2:1-7 . doi: 10.5098/hmt.v2.4.3005

[12] Iachachene F, Haddad Z, Oztop HF, Abu-Nada E (2019) Melting of phase change materials in a trapezoidal cavity: Orientation and nanoparticles effects. J Mol Liq \#pagerange\# . doi: 10.1016/j.molliq.2019.03.051

[13] Khodadadi JM, Hosseinizadeh SF (2007) Nanoparticle-enhanced phase change materials (NEPCM) with great potential for improved thermal energy storage. Int Commun Heat Mass Transf 34:534-543 . doi: 10.1016/j.icheatmasstransfer.2007.02.005

[14] (2013) ANSYS Fluent Theory Guide 